\title{
Información archivística e información orgánica: un análisis conceptual de la literatura brasileña
}

\author{
Por Marta-Lígia Pomim-Valentim y Mariana Lousada
}

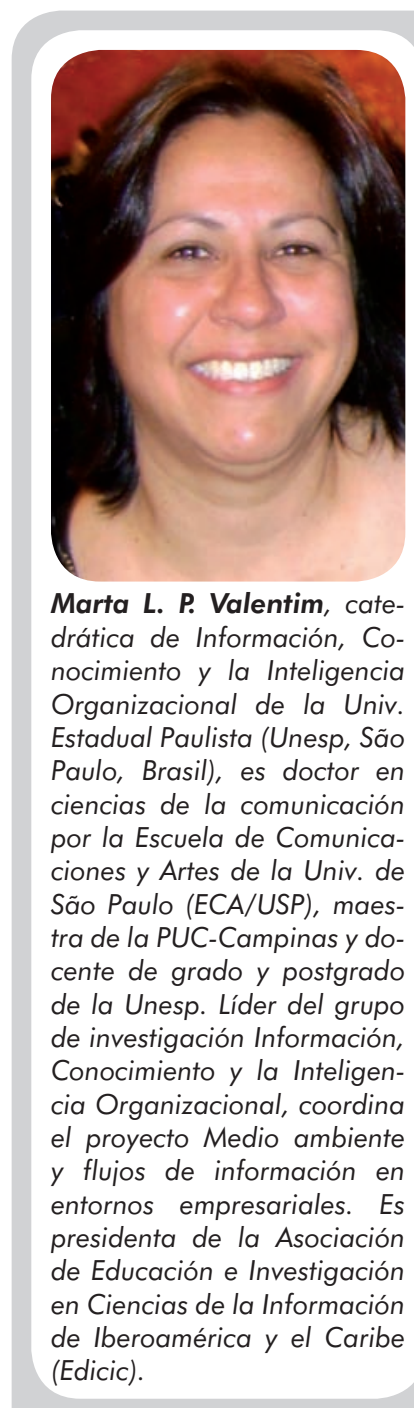

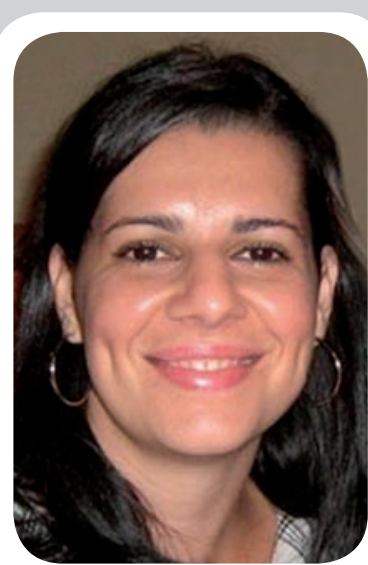

Mariana Lousada tiene una maestría en ciencias de la información y una licenciatura en archivística por la Universidad Estadual Paulista (Unesp, São Paulo, Brasil). Es miembro del grupo de investigación Información, Conocimiento y la Inteligencia Organizacional.

Resumen: La información, cada vez más, se ha convertido en un recurso fundamental para las organizaciones que quieren ser competitivas en el mercado internacional. Por esta razón, el análisis correcto de los tipos de información que están presentes en ellas es fundamental para que puedan alcanzar los más altos niveles de rendimiento. Se presenta un análisis de la literatura del área, y se definen conceptos sobre información orgánica e información archivística en entornos empresariales. Se resalta que éste es un campo teórico todavía en formación, que aún da lugar a debates intensos. Se señalan los elementos que caracterizan y distinguen esos dos tipos de información.

Palabras clave: Información orgánica, Información archivística, Archivística, Ciencia de la información, Epistemología.

Title: Archival information and organic information: a conceptual analysis of the Brazilian literature

Abstract: Information has increasingly become a crucial resource for organizations that want to remain competitive in the market. For this reason, analysis and a correct understanding of informational types that are present in these environments become relevant to achieving the highest levels of performance. The aim of this paper is to review the literature of the concepts of organic and archival information within the organizational context/business environments. This is still an emerging theoretical field and therefore is conducive to intense discussions. We point out elements that help to characterize and distinguish these two types of information.

Keywords: Organic Information, Archivist information, Archivology, Information science, Epistemology.

Valentim, Marta L. P.; Lousada, Mariana. "Información archivística e información orgánica: un análisis conceptual de la literatura brasileña”. El profesional de la información, 2010, julio-agosto, v. 19, n. 4, pp. 404-408.

DOI: $10.3145 /$ epi.2010.jul.10

\section{Información orgánica}

\section{CONCEPTUALIZAR EL} TÉRMINO INFORMACIÓN ORGÁNICA es una tarea difícil de realizar dentro de los parámetros teóricos de la archivística, porque es un concepto relativamente nuevo en la literatura, que lo convierte en blanco de las preguntas de los estudiosos.

Los teóricos que más han contribuido a la consolidación de este concepto son los canadienses y los estadounidenses, que ya iniciaron estudios sobre este tema en los años 90. Según Moreno (2007, p. 9) “el concepto de información archivística o de la información orgánica es reciente en la literatura del área y requiere todavía una profundización teórica".

Después de examinar la bibliografía existente, como referencia teórica de este trabajo fue adoptada la definición de los investigadores Rousseau y Couture (1998, p. 64): "la información puede ser orgánica, o sea, elaborada como parte de la misión de una organización; o no orgánica, producida fuera de ésta”.

La información orgánica es un resultado de las actividades realizadas en la organización; se produce en el ejercicio de las tareas administrativas, como registro físico de las operaciones de una determinada actividad, tarea o toma de decisión.

Lopes (1996, p. 32) afirma que "[...] es orgánica la información relativa a la persona u organización que la ha acumulado", es decir, la información orgánica es inherente 
a la organización/institución que la ha generado siendo, por lo tanto, fruto de los componentes que la integran. Podemos considerar también que la combinación de unos con otros, es decir, el cruce de estos componentes puede generar nueva información, también de carácter orgánico.

Para Carvalho y Longo (2002, p. 115), “[...] información orgánica es un conjunto de informaciones sobre un tema en particular, materializado en documentos de archivo, que a su vez mantienen relaciones orgánicas entre sí y fueron producidos en la realización de actividades y funciones de la organización". Las informaciones orgánicas, organizadas y ordenadas, forman los archivos de la institución.

Las informaciones de esta naturaleza se producen en todos los sectores de la organización. Para determinar cuáles son los productores potenciales y cuáles son los más importantes, hay que realizar un análisis detallado de los flujos informacionales, mapeando todos los sectores. Esto puede hacerse mediante entrevistas, cuestionarios y observación, siendo el objetivo definir cuáles son las informaciones que se producen en cada sector, y cuáles de ellas pueden convertirse en insumos para la toma de decisiones.

Para convertirse en determinantes en el proceso de toma de decisiones las informaciones deben ser de carácter formal, es decir, estar registradas en soportes, y deben ser impuestas por los órganos o personas competentes para determinado propósito. Para Pazin (2005, p. 16) "estos documentos son producidos de acuerdo con la estructura jurídica, el sistema fiscal y las actividades técnicas llevadas a cabo".

La información contenida en los documentos es de carácter orgánico, debido a que todos los documentos son producidos internamente en el ejercicio de las actividades organizacionales. Observamos el gran número y variedad de este tipo de información.

Según Stoner y Freeman (1992, p. 489) la información obtenida dentro de la organización debe tener cuatro características:

- Calidad: cuanto más eficaz y adecuada sea, mayor será la confianza con la que la dirección puede tomar una decisión.

- Oportunidad: debe estar disponible para la persona correcta en el momento oportuno.

- Cantidad: normalmente a la dirección se le entrega excesiva cantidad de información, que no toda es útil y pertinente. Esto puede afectar a la correcta toma de decisiones, ya que puede pasar inadvertido algún dato importante. No importa la cantidad sino la calidad, y hay que intentar que la cantidad sea mínima, a poder ser una sola hoja.

- Pertinencia: debe ser dirigida a las personas adecuadas, de modo que sea importante para su desempeño profesional.

\section{"La información orgánica es producto de las actividades realizadas en la organización"}

\section{Información archivística}

Lo qué sucede en los debates sobre el concepto de información orgánica se aplica también a la fundamentación de la información archivística. Según Lopes (1996, p.

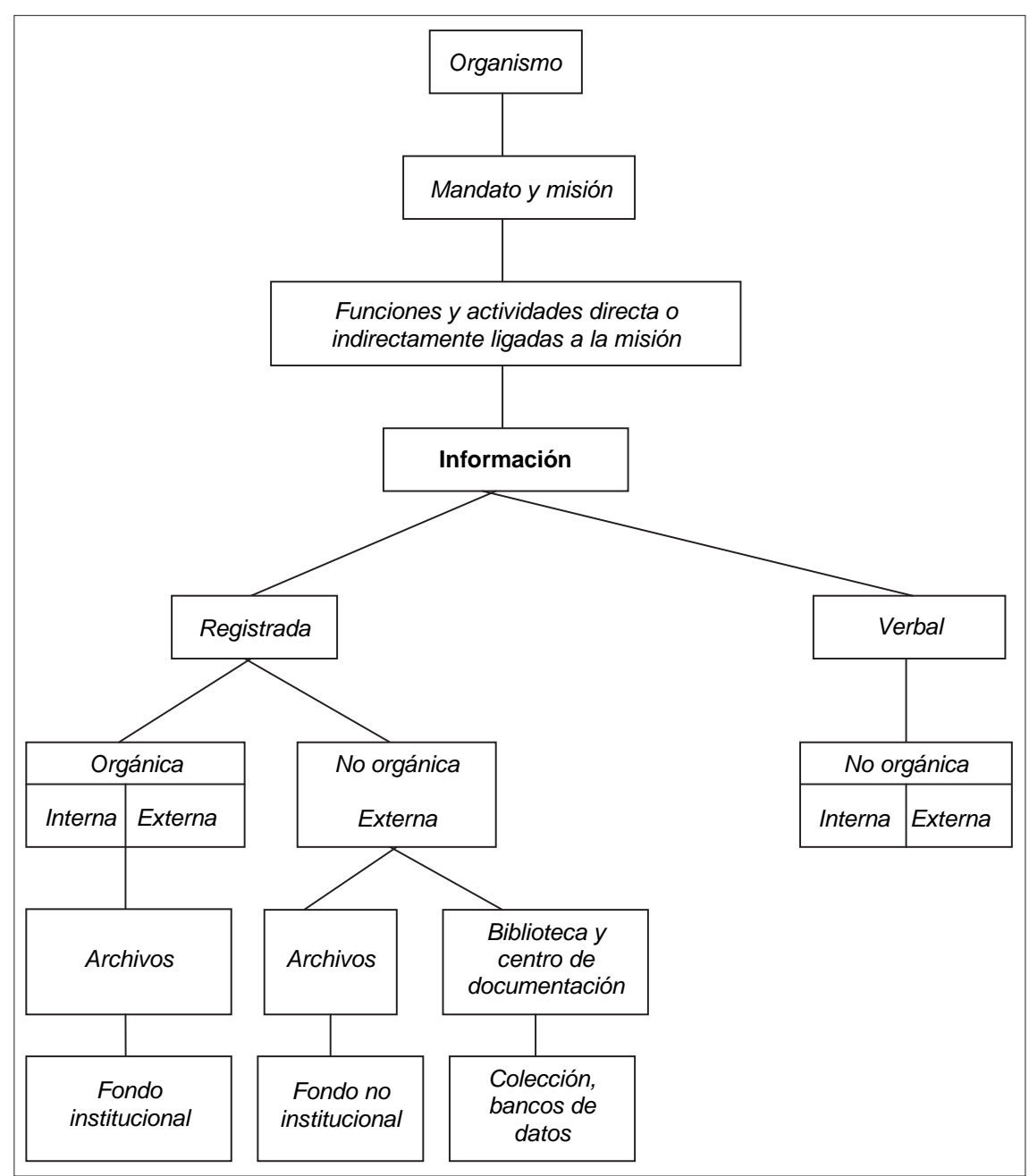

Figura 1. Origen y naturaleza de la información en un organismo. Adaptado de Rousseau y Couture (1998, p. 64) 
30), los debates y las ideas acerca de la información archivística han sido descuidados por los teóricos del área. El autor añade que "el concepto de información archivística está prácticamente ausente en los textos más conocidos de la literatura mundial especializada y en las propuestas de soluciones para los problemas de los archivos". En los últimos años esta situación ha ido cambiando, y se han realizado algunos estudios y publicaciones sobre la misma.

Información archivística es un concepto más amplio que información orgánica. Mientras ésta se produce sólo en el ambiente interno a la organización, la información archivística se produce en las relaciones entre la organización y sus stakeholders $^{1}$ : correspondencia entre organizaciones, comunicaciones de órganos de gobierno, así como la que se tramita a través de sistemas informáticos interconectados.

Rousseau y Couture (1998, p. 64) proponen un esquema que detalla los tipos de información establecidos dentro de la organización:

\section{Análisis comparativo entre los conceptos}

Podemos realizar un análisis comparativo de los conceptos sobre información orgánica e información archivística para comprender mejor los problemas que interfieren con la correcta definición de los términos.

En primer lugar presentamos (tabla 1) las definiciones encontradas en la literatura respecto a la información orgánica. Es de notar que hay pocos autores que discutan este concepto.

Los investigadores Lopes (1996), Rousseau y Couture (1998), Carvalho y Longo (2002), Lousada y Valentim (2008) consideran la información orgánica como un producto para ejecución de las funciones, actividades y tareas realizadas dentro de la organización, tratando de lograr su misión, metas y objetivos. Su carácter orgánico viene dado por el hecho de ser producida internamente.

En la tabla 2 presentamos los conceptos de la literatura sobre la información archivística.

Algunos autores convergen en la definición de información orgánica e información archivística. Es el caso de: Rousseau y Couture (1998), Lopes (2000) citado en Calderón et al. (2004), Lousada y Valentim (2008). Para éstos la información archivística se produce en el cumplimiento de las relaciones con otras organizaciones como consecuencia de la realización de las actividades y tareas, es decir, se genera dentro o fuera de la organización. Sostienen que la información archivística es más amplia que la orgánica y consideran que los dos términos no son sinónimos.

Bellotto (2002), Mariz (2005), Fonseca (2005) y Moreno (2007) equiparan el concepto orgánico al archivístico, para ellos no hay distinción, es decir, el entorno de producción no se considera como un medio de caracterización.
A partir de este análisis es posible hacer algunas observaciones sobre las corrientes teóricas. Cabe destacar una vez más que por ser éste un tema nuevo son pocos los autores que discuten la información orgánica y por lo tanto, el análisis se vuelve más difícil, ya que existen pocos medios para establecer una comparación y hay poca discusión sobre la problemática en sí.

Existen dos perspectivas teóricas que destacan en este tema. La primera, más moderna, e identificada por Fonseca (2005, p. 60) como "archivística pos-moderna" o "archivística pos-custodial" formada principalmente por los investigadores canadienses. Entre ellos identificamos e integramos a Rousseau y Couture, Lopes, Carvalho y Longo, y Lousada y Valentim. Estos investigadores fueron utilizados en este artículo como parte de la fundamentación teórica, ya que entienden el concepto de información orgánica de la misma manera.

La segunda corriente está formada por Bellotto, Mariz, Fonseca, y Moreno, y su enfoque reside en la información como algo intrínseco al documento de archivo, es decir, la información archivística es inherente al soporte. Según estos autores, la información archivística es orgánica por la relación entre los documentos, no por su entorno de producción. Esta cadena más tradicional todavía ve la archivística como una ciencia que reconoce los archivos como objetos y no la información que contienen.

\begin{tabular}{|c|c|}
\hline Autores & Conceptos encontrados en la literatura sobre información orgánica \\
\hline Lopes $(1996$, p. 32) & “[...] es orgánica la información relativa a la persona u organización que la ha acumulado" \\
\hline $\begin{array}{l}\text { Rousseau y Couture } \\
(1998, \text { p. 291) }\end{array}$ & $\begin{array}{l}\text { "[...] la información puede ser orgánica, es decir, es elaborada, enviada o recibida en el ámbito } \\
\text { de su misión” }\end{array}$ \\
\hline $\begin{array}{l}\text { Carvalho y Longo } \\
(2002, \text { p. 115) }\end{array}$ & $\begin{array}{l}\text { "[...] la información orgánica es una recopilación de información sobre un tema en particular, } \\
\text { materializado en documentos de archivo, que a su vez mantiene relaciones orgánicas entre sí } \\
\text { y fueron producidas en el cumplimento de las actividades y funciones de la organización" }\end{array}$ \\
\hline $\begin{array}{l}\text { Lousada y Valentim } \\
(2008, \text { p. } 254)\end{array}$ & $\begin{array}{l}\text { "La información orgánica es producida internamente, siendo producto resultante de la aplica- } \\
\text { ción de las funciones y actividades de la organización" }\end{array}$ \\
\hline
\end{tabular}

Tabla 1. Concepto de información orgánica 


\begin{tabular}{|c|c|}
\hline Autores & Conceptos encontrados en la literatura sobre información archivística \\
\hline $\begin{array}{l}\text { Rousseau y Couture } \\
(1998, \text { p. 64) }\end{array}$ & “[...] la información producida fuera del ámbito de la misión de un organismo". \\
\hline $\begin{array}{l}\text { Lopes (2000) citado } \\
\text { en Calderón et al. } \\
(2004, \text { p. } 100)\end{array}$ & $\begin{array}{l}\text { "[...] la naturaleza de las informaciones archivísticas es específica, se trata de informaciones re- } \\
\text { gistradas en soporte definido, acumuladas por un individuo o por un organismo que es al mismo } \\
\text { tiempo productor y receptor" }\end{array}$ \\
\hline $\begin{array}{l}\text { Bellotto } \\
\text { (2002, p. 23) }\end{array}$ & $\begin{array}{l}\text { "[...] la información archivística sobre las informaciones de otra naturaleza: se produce en el } \\
\text { contexto del ejercicio de las funciones/objetivos que se proponen las entidades. Por ello, las } \\
\text { informaciones son orgánicas, porque guardan entre sí las mismas relaciones que existen entre } \\
\text { las atribuciones, competencias, funciones y actividades de las entidades" }\end{array}$ \\
\hline $\begin{array}{l}\text { Fonseca } \\
(2005, \text { p. 59) }\end{array}$ & $\begin{array}{l}\text { "El objeto de la archivística, en la perspectiva de un nuevo paradigma, se traslada del 'archivo' } \\
\text { hacia la información archivística o 'información registrada orgánica', un término acuñado por } \\
\text { los archiveros canadienses para describir la información generada por los procedimientos admi- } \\
\text { nistrativos y estructurado para permitir una recuperación en que el contexto organizacional de } \\
\text { estos procesos sea el punto de partida" }\end{array}$ \\
\hline $\begin{array}{l}\text { Mariz } \\
(2005, \text { p. } 1)\end{array}$ & $\begin{array}{l}\text { "[...] se entiende que la información archivística, también llamada información registrada or- } \\
\text { gánica, se refiere a documentos producidos por un organismo (persona o institución), como } \\
\text { resultado de sus actividades a lo largo de su existencia" }\end{array}$ \\
\hline $\begin{array}{l}\text { Moreno } \\
\text { (2007, p. 9) }\end{array}$ & $\begin{array}{l}\text { "[...] la diferencia de la información archivística en relación con las informaciones de otra natu- } \\
\text { raleza es que ella es producto de las actividades de un determinado organismo [...] este tipo } \\
\text { específico de información se denomina orgánica por guardar entre sí las mismas relaciones que } \\
\text { se forman entre las competencias y actividades de las organizaciones" }\end{array}$ \\
\hline $\begin{array}{l}\text { Lousada y Valentim } \\
\text { (2008, p. 254, } \\
\text { destaque nuestro) }\end{array}$ & $\begin{array}{l}\text { “[...] la información no orgánica es aquella producida externamente a la organización, pero se } \\
\text { relaciona con la organización mediante actividades y/o transacciones, es decir, información no } \\
\text { orgánica puede, también, ser considerada sinónimo de información archivística” }\end{array}$ \\
\hline
\end{tabular}

Tabla 2. Concepto de información archivística

\section{"Los autores de la corriente tradicional consideran información archivística y información orgánica sinónimas"} (2)

Por lo tanto podemos concluir que la corriente considerada más tradicional discute la información orgánica, pero con una visión más reduccionista, en cuanto que consideran información archivística y información orgánica sinónimos.

\section{Consideraciones finales}

Defendemos que la información orgánica y la información archivística son conceptos distintos y por lo tanto no pueden considerarse sinónimos. Buscamos demostrar e ilustrar que esta equivalencia no debe hacerse.

Los términos orgánico y archivístico son relativos a distintos contextos informacionales. Sin embargo, debemos destacar que a pesar de ser conceptos distintos están

\begin{tabular}{|l|l|}
\hline $\begin{array}{c}\text { Corrientes teóricas sobre } \\
\text { información archivística e } \\
\text { información orgánica }\end{array}$ & \multicolumn{1}{c|}{ Autores } \\
\hline Tradicional/conservadora & $\begin{array}{l}\text { Bellotto, Mariz, Fonseca, y } \\
\text { Moreno }\end{array}$ \\
\hline $\begin{array}{l}\text { Archivística pos-moderna o } \\
\text { archivística pos-custodial }\end{array}$ & $\begin{array}{l}\text { Rousseau y Couture, Lopes, } \\
\text { Carvalho y Longo, y Lousada y } \\
\text { Valentim }\end{array}$ \\
\hline
\end{tabular}

Tabla 3. Principales corrientes teóricas sobre archivos

relacionados entre sí, ya que ambos tipos de información se dan en los ambientes organizacionales. El Diccionario Aurélio define orgánico como "algo que se relaciona con los órganos, la organización, los seres organizados". En este sentido, podemos considerar que presenta vinculación directa con la institución que la generó, a saber, el entorno de producción.

http://www.dicionariodoaurelio. com/dicionario.php $? P=$ Organico

La información orgánica revela la interrelación, el contexto de su existencia y también de creación. Por lo tanto, es posible reconocer claramente el contexto de producción. Como destacan Fauvel y Valentim (2008, p. 238) "la información orgánica es un tipo de in-
“Información orgánica e información archivística son conceptos distintos"

formación archivística, ya que se produce sólo en el ámbito interno a la organización".

La información orgánica es por naturaleza archivística pues es el resultado de las acciones de la organización/institución. Sin embargo, la información archivística no siempre es orgánica en el sentido de que no se produce necesariamente en una organización específica, es decir, puede haber sido producida en lugares externos a la organización. 
De la sistematización de los cuadros conceptuales podemos señalar también, que los debates sobre el tema son superficiales y que requieren una mayor clarificación y debate. La definición del concepto de información orgánica, es todavía muy reciente, por esta razón, la equivalencia entre los términos de la información orgánica y información archivística debe ser mejor explotada.

\section{Nota}

1. Stakeholders son todos los actores que interactúan con la organización: clientes, competidores, accionistas, consultores, etc.

\section{Referencias}

Bellotto, Heloísa L. Como fazer análise diplomática e análise tipológica de documentos de arquivo. São Paulo: Imprensa Oficial do Estado de São Paulo, 2002, ISBN 8570601336. http://www.arquivoestado.sp.gov.br/saesp/texto pdf_17_Como\%20fazer\%20analise\%20diploma tica\%20e\%20analise\%20tipologica.pdf

Calderon, Wilmara R.; Cornelsen, Julce M. Pavezi, Neiva; Lopes, Maria A. "O processo de gestão documental e da informação arquivística no ambiente universitário". Ciência da informação, 2004, set.-dez., v. 33, n. 3, pp. 97-104. http://www.scielo.br/pdf/ci/v33n3/a11v33n3.pdf

De-Carvalho, Elizabeth L.; Longo, Rose-Mary J. "Informação orgânica: recurso estratégico para tomada de decisão pelos membros do Conselho de Administração da UEL". Informação \& informação, 2002, jul.-dez., v. 7, n. 2, pp. 113-33.

http://www.uel.br/revistas/uel/index.php/infor macao/article/view/1703/1454

Fauvel, Thais H. F.; Valentim, Marta L. P. “Informação orgânica como subsídio para o processo de inteligência competitiva organizacional". En: Valentim, M. L. P. (Org.). Gestão da informação e do conhecimento no âmbito da ciência da informação. São Paulo: Polis: Cultura Acadêmica, 2008, pp. 229-241, ISBN 8572280280.

Fonseca, Maria O. Arquivologia e ciência da informação. Rio de Janeiro: FGV Editora, 2005, ISBN 8522505039.

Lopes, Luis-Carlos. Informação e os arquivos: teorias e práticas. São Carlos: Edufscar, 1996, ISBN 8522801916.

Lousada, Mariana; Valentim, Marta L. P. "Informação orgânica como insumo do processo decisório empresarial". En: Valentim, Marta L. P. (Org.). Gestão da informação e do conhecimento no âmbito da Ciência da Informação. São Paulo, Polis: Cultura Acadêmica, 2008, pp. 243-261, ISBN 8572280280.

Mariz, Anna-Carla A. Arquivos públicos brasileiros: a transferência da informação na Internet. 2005. 187f. Tese (Doutorado), Programa de Pós-
Graduação em Ciência da Informação, Escola de Comunicação, Univ. Federal do Rio de Janeiro, 2005.

http://www.asocarchi.cl/DOCS/43.PDF

Moreno, Nádina A. "A informação arquivística e o processo de tomada de decisão". Informação \& sociedade: Estudos, 2007, jan.-abr., v. 17, n. 1, pp. 9-19.

http://www.ies.ufpb.br/ojs2/index.php/ies/article/ view/483/626

Pazin, Márcia. Arquivos de empresas: tipologia documental. São Paulo: Associação dos Arquivistas de São Paulo, 2005.

Rousseau, Jean-Yves; Couture, Carol. "O lugar da arquivística na gestão da informação". En: Rosseau, Jean-Yves; Couture, Carol. Os fundamentos da disciplina arquivística. Lisboa: Dom Quixote, 1998, p. 61-76, ISBN 9789722014281.

Stoner, James A. F.; Freeman, R. Edward. Administração. 5a ed. Rio de Janeiro: Prentice Hall do Brasil, 1992, ISBN 8521611684.

\section{Marta-Lígia Pomim-Valentim.} Departamento de Ciência da Informação. Universidade Estadual Paulista Júlio de Mesquita Filho. valentim@valentim.pro.br

Mariana Lousada

marianalousada@hotmail.com

\section{Recibe el sumario de EPI por email}

Sé el primero en conocer el contenido de cada nuevo número de EPI. Mediante el servicio Alerting (servicio de alerta), cuando salga un nuevo número de EPI puedes recibir un email con el sumario.

\section{Para registrarte}

Entra en la web de EPI-MetaPress con tus claves de acceso:

http://elprofesionaldelainformacion.metapress.com/ Si no eres suscriptor también puedes registrarte, pues este servicio es gratuito.

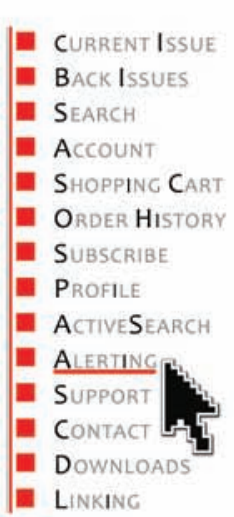

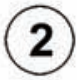

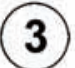

Alerting Publications

듸의히 하

\section{1 to 1 of 1}

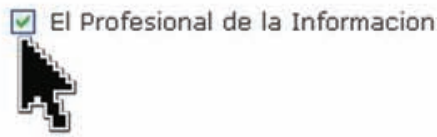

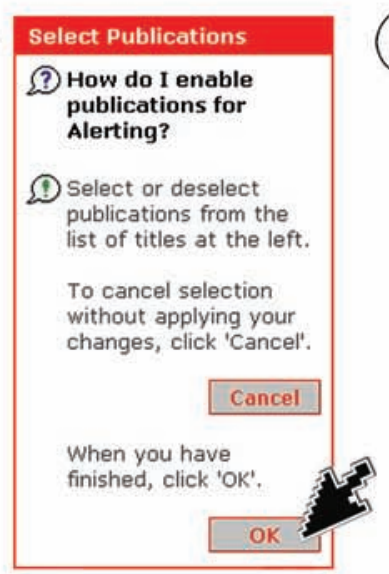

4

Confirmation

D Congratulations!

You are currently registered with Alerting for these titles.

If you would like to modify your selections, click 'Continue'.

Continue

If you are satisfied with your selections, click 'OK'. 